Integrating storytelling and quantitative career assessment

Mary McMahon ${ }^{1 *}$, Jenny Bimrose ${ }^{2}$, Mark Watson ${ }^{3} \&$ Peyman Abkhezr ${ }^{4}$

1. School of Education, The University of Queensland, Brisbane, Australia

2. Institute for Employment Research, The University of Warwick, Coventry, UK

3. School of Behavioural and Lifestyle Sciences, Faculty of Health Sciences, Nelson Mandela University, Port Elizabeth, South Africa

4. School of Applied Psychology, Griffith University, Gold Coast, Australia

*Corresponding Author: Dr Mary McMahon, School of Education, The University of Queensland, Brisbane, Australia. Email: marymlmcmahon@uq.edu.au

This is a pre-print version of:

McMahon, M., Bimrose, J., Watson, M., \& Abkhezr, P. (2019). Integrating storytelling and quantitative career assessment. International Journal for Educational and Vocational Guidance, 1-22. https://doi.org/10.1007/s10775-019-09415-1 


\begin{abstract}
Combining quantitative career assessment with narrative career counselling is a career counselling challenge. The Integrative Structured Interview (ISI) facilitates this integration through the narration of career stories based on quantitative scores, such as those of the SelfDirected Search. The aims of this single case research were to: (a) examine the process of an Integrative Structured Interview with a participant, and (b) explore it from the participant and interviewer perspectives using an interpersonal process recall interview. The results suggest the benefits of the ISI process and a need for further research with a range of client groups.
\end{abstract}

Keywords: Integrative Structured Interview; Interpersonal Process Recall; quantitative career assessment; Systems Theory Framework; narrative career counselling

Please cite as:

McMahon, M., Bimrose, J., Watson, M., \& Abkhezr, P. (2019). Integrating storytelling and quantitative career assessment. International Journal for Educational and Vocational Guidance, 1-22. https://doi.org/10.1007/s10775-019-09415-1

This is a pre-print version of:

McMahon, M., Bimrose, J., Watson, M., \& Abkhezr, P. (2019). Integrating storytelling and quantitative career assessment. International Journal for Educational and Vocational Guidance, 1-22. https://doi.org/10.1007/s10775-019-09415-1 


\title{
Integrating storytelling and quantitative career assessment
}

\author{
Introduction \\ "the more you think about these things, the more you remember or realise"
}

These words of Nadya, the participant in the present single case research, were spoken in an Interpersonal Process Recall (IPR; Kagan, 1980, 1984) interview which followed her experience of the Integrative Structured Interview process (ISI; McMahon \& Watson, 2012b). The ISI is a structured narrative interview based on the quantitative scores of a career assessment instrument, in the case of this research the three-letter code produced by Holland's (1985) Self-Directed Search. The ISI addresses a pressing challenge in career counselling, specifically that of integrating quantitative assessment with narrative career counselling. The present research is important because it responds to a further challenge in career counselling to strengthen its evidence base, as well as the need for research that focuses on practice relevant topics and is accessible to practitioners (Schultheiss, 2017). The aims of the present research were to: a) examine the process of an Integrative Structured Interview with a participant, and b) explore it from the participant and interviewer perspectives using an Interpersonal Process Recall interview. Consequently, the article reports on an interview based on the ISI process with Nadya, an adult Australian participant, and the subsequent IPR interviews with Nadya and her interviewer.

\section{The Changing Face of Career Counselling}

Career development no longer occurs in a predictable, stable and linear work world. Present conditions in the world of work challenge and outdate most career development theories from the last century. This has resulted in the development and redevelopment of career theories,

This is a pre-print version of:

McMahon, M., Bimrose, J., Watson, M., \& Abkhezr, P. (2019). Integrating storytelling and quantitative career assessment. International Journal for Educational and Vocational Guidance, 1-22. https://doi.org/10.1007/s10775-019-09415-1 
career assessment and career counselling models as a response to the increasing complexity and uncertainties evident in the world of work (Watson, 2016).

A common theme in several newer theoretical developments is their emphasis on narrative approaches to career counselling which empower clients to construct a career narrative involving a continuous and coherent re-authoring narrative process (Cardoso, Goncalves, Duarte, Silva, \& Alves, 2016). The Integrative Structured Interview (ISI; McMahon \& Watson, 2010, 2012a, 2012b) incorporates quantitative career assessment results into a narrative career interview process.

\section{The Integrative Structured Interview Process}

While quantitative career assessment has remained dominant in recent decades (Sampson, 2009), there is less agreement as to how to use quantitative career assessment qualitatively in narrative career counselling (Patton \& McMahon, 2014) and insufficient practical applications in the literature to guide career practitioners (Watson, 2017). The first comprehensive book on qualitative career assessment (McMahon \& Watson, 2015) devoted a number of chapters to the qualitative use of quantitative career assessment. A theme running through the literature is that the quantitative/qualitative use of assessment in career counselling both serve their purpose (Sampson, Peterson, Osborn, \& Hayden, 2015) and that career counselling would benefit from a multistoried process that addresses the fluid, complex contexts within which individual career development takes place (McMahon, Watson, \& Lee, 2018; Watson \& McMahon, 2015a). This is not a new suggestion as its historical roots can be traced back to Donald Super (1957) and even earlier. However, the suggestion does raise the issue of how to craft stories from scores.

One such way is the Integrative Structured Interview (ISI), a qualitative practical application of the story telling approach to career counselling (McMahon \& Watson, 2010, This is a pre-print version of:

McMahon, M., Bimrose, J., Watson, M., \& Abkhezr, P. (2019). Integrating storytelling and quantitative career assessment. International Journal for Educational and Vocational Guidance, 1-22. https://doi.org/10.1007/s10775-019-09415-1 
2012a, 2012b) which has its origins in the Systems Theory Framework (STF; Patton \& McMahon, 2014) of career development. Similar to other narrative approaches to career counselling, the story telling approach positions connectedness, meaning making and agency as core process constructs. Unlike other narrative approaches and consistent with the story telling approach's foundation in the STF, two further processes of reflection and learning are made explicit as core process constructs. The story telling approach applies systems thinking to career counselling and assessment and encourages clients to actively reflect on and contextualise the multiple stories and settings of their lives. In essence, the ISI is based on the five core process constructs of connectedness, meaning making, agency, learning and reflection (Watson \& McMahon, 2015b). Consistent with its parent theoretical framework, the ISI is a systemic interview that provides a structured process within which clients can reflect on the meaning and relatedness of themes in their lives, thus discovering the stories embedded in their quantitative scores.

The ISI demonstrates three important principles. First, it provides guidelines for the construction of a qualitative career assessment process (Watson \& McMahon, 2014), that is a co-constructed, mutual learning process based on the career counselling relationship, narrative career counselling, and knowledge of quantitative career assessment instruments. Second, the ISI is systemic because of its theoretical foundation in the Systems Theory Framework (STF) of career development (Patton \& McMahon, 2014) which also underpins the story crafting questions emanating from the story telling approach to career counselling.

The third principle is systems contextualisation through which clients holistically consider the qualitative stories embedded in their quantitative scores. Consistent with the STF, learning and holistic reflection occur as clients consider the multiple contexts of their lives (work and nonwork) over time (past, present and future stories) (McMahon, Watson, \& This is a pre-print version of:

McMahon, M., Bimrose, J., Watson, M., \& Abkhezr, P. (2019). Integrating storytelling and quantitative career assessment. International Journal for Educational and Vocational Guidance, 1-22. https://doi.org/10.1007/s10775-019-09415-1 
Zietsman, 2018; Watson \& McMahon, 2018). Learning is also evident as clients make meaning of their quantitative career assessment scores in relation to the interdependent and recursively connected individual, social and environmental-societal systems within which they live (McMahon, Watson, Chetty, \& Hoelson, 2012). Stimulated by the ISI, this reflection and learning process results in clients crafting a future, integrated career story.

The structure of the ISI is framed within a series of story crafting questions (McMahon \& Watson, 2012a) that enable clients to holistically connect their life roles from what was previously a fragmented and disconnected career story. Descriptions of the ISI (Watson, 2017; Watson \& McMahon, 2014, 2015b) and its use with quantitative career assessment instruments have been described in relation to Holland's (1985) Self-Directed Search (McMahon \& Watson, 2012b) and Super's Revised Work Values Inventory (Zytowski, 2006) (Watson \& McMahon, 2014).

The ISI consists of thirteen story crafting questions based on the SDS that are asked across six sections. The first three story crafting questions, in the initial ISI section on Crafting a story about the quantitative scores, encourage clients to reflect, in a meaning making process, on their understanding of the quantitative results of a specific career assessment instrument which would have been completed prior to the ISI process (e.g., How would you explain the order of your three-letter code?). In the second structured step of the ISI, Crafting a story about the relative value of the quantitative scores, clients elicit meaning by exploring the quantitative scores more holistically and qualitatively through a further two story crafting questions (e.g., If you were to locate your letter on a scale of 1 to 10 where 1 was least important and 10 was most important, where would you locate the first letter, the second letter, and the third letter?). Such exploration may involve reflecting on differences in scores or the relative values given to scores.

This is a pre-print version of:

McMahon, M., Bimrose, J., Watson, M., \& Abkhezr, P. (2019). Integrating storytelling and quantitative career assessment. International Journal for Educational and Vocational Guidance, 1-22. https://doi.org/10.1007/s10775-019-09415-1 
In the third section of the ISI, Crafting a story about the quantitative scores in life contexts, clients respond to four story crafting questions that encourage the systems contextualisation of the quantitative scores by telling stories specifically in relation to their life roles (e.g., In what ways is the third letter of your code evident in your life?). This contextualisation continues in the fourth section, Crafting a story about the quantitative score in work contexts. Here clients consider two story crafting questions that bring the reflective and learning process closer to an exploration of their past, present and future work role (i.e., both paid and unpaid work) by telling stories related to their work roles (e.g., Of all your work responsibilities which do you find most satisfying or rewarding, and which are least satisfying and rewarding, and how do you relate these to your three-letter code?).

There is only one story crafting question in the fifth section of the ISI process, Crafting a story about the quantitative scores through personal reflection (i.e., What personal qualities have you identified in your reflection so far that are most important to you?). This question calls for further contextualisation and meaning making in that the client considers the ISI process in relation to personal qualities (e.g., strengths and weaknesses). This section requires a deeper reflection level from the client, with greater depth also called for in the sixth section of the ISI process, Crafting an integrative future story using the quantitative scores and past and present experience. Similar to the fifth section, there is a single story crafting question in this sixth and final section that encourages the client to construct a future career story based on the processes of meaning making, connectedness, reflection, learning and agency they have engaged in through the previous five sections of the ISI process (i.e., Based on your reflection in the previous questions, what could you look for in future work opportunities in order to achieve greater work satisfaction?). While the ISI is guided by the 13 story crafting questions, interviewers may, as appropriate, use further communication This is a pre-print version of:

McMahon, M., Bimrose, J., Watson, M., \& Abkhezr, P. (2019). Integrating storytelling and quantitative career assessment. International Journal for Educational and Vocational Guidance, 1-22. https://doi.org/10.1007/s10775-019-09415-1 
skills such as reflections and paraphrases as probes to stimulate deeper reflection or seek further information.

Consistent with a call for "scientific endeavors that promote new knowledge in a manner that is accessible to practitioners" (Schultheiss, 2017, p.168), the aims of the present research were to: a) examine the process of an Integrative Structured Interview with a participant, and b) explore it from the participant and interviewer perspectives using an Interpersonal Process Recall interview.

\section{Method}

To address these aims of the research, a qualitative exploratory descriptive approach was employed using a single case. Single case studies have previously been used successfully to evaluate career counselling interventions (e.g., Cardoso et al., 2016; Hartung \& Vess, 2016). A single case was selected for the purpose of this research because it provided the opportunity for in-depth interrogation of the ISI.

\section{Recruitment and Participant}

Subsequent to obtaining ethical clearance, participants were recruited using purposive sampling as a non-probability sampling technique (Ritchie, Lewis, McNaughton Nicholls, \& Ormston, 2013). Information on the research was provided to final year students in a program of education at an Australian university who were changing careers as a result of their study. The researchers provided potential participants with a Participant Information Sheet and Consent Form. The interview reported here was conducted in Australia with Nadya (a pseudonym) who was the first participant to provide consent.

Nadya is an Australian 39 year-old single female student completing a one year postgraduate qualification. She already has a degree in a field from the creative industries. At the time of the interview, Nadya had completed her program of study and was preparing to This is a pre-print version of:

McMahon, M., Bimrose, J., Watson, M., \& Abkhezr, P. (2019). Integrating storytelling and quantitative career assessment. International Journal for Educational and Vocational Guidance, 1-22. https://doi.org/10.1007/s10775-019-09415-1 
transition from study into her chosen occupation. Her reason for participating in the research was to gain some clarity about her career choice.

\section{Instruments}

The Self-Directed Search (Holland, 1985) is based on Holland's (1997) personenvironment typology theory and is universally acknowledged in the career literature as a popular quantitative assessment of career interests (Watson \& McMahon, 2014). Quantitative scoring of the SDS provides individuals with a three-letter code that could be matched to the three-letter codes of occupations listed in the Occupations Finder (Shears \& Harvey-Beavis, 2012).

The first phase of the research, the reflective interview, comprised a four-part interview inclusive of the ISI designed to assist participants reflect on their career change. Part A included five demographic questions. Part B included seven questions related to university study. Part C of the interview contained the ISI questions (see McMahon \& Watson, 2012b). Part D contained eight questions about preparing for transition from university. This research reports on Part C.

The second phase of the research procedure investigated the interview experiences of the participant and the interviewer using an Interpersonal Process Recall (IPR, Kagan, 1980, 1984) inquiry which provided an opportunity for both the participant and the interviewer to listen to the recording of their session in the presence of an inquirer. By stopping the recording at points that were significant and meaningful to them, the participant and interviewer could explicate their thinking on the interview at those points.

IPR has been used across many disciplines within the helping professions (Larsen, Flesaker, \& Stege, 2008), and has been proposed for use in career psychology to "understand the meaning counselors and their clients are making in career counseling" (Heppner \& This is a pre-print version of:

McMahon, M., Bimrose, J., Watson, M., \& Abkhezr, P. (2019). Integrating storytelling and quantitative career assessment. International Journal for Educational and Vocational Guidance, 1-22. https://doi.org/10.1007/s10775-019-09415-1 
Integrating storytelling and assessment

Heppner, 2003, p. 445). An IPR interview provided an opportunity to investigate the little researched ISI process. The IPR inquirer remained nonjudgmental and supportive. During the IPR inquiry sessions, the inquirer avoided leading questions and adopted a 'learning by discovery' approach (Kagan, 1980, 1984) towards both the participant and the interviewer.

\section{Procedure}

Subsequent to participant consent, interviews were arranged at a time and place convenient to both the participant and the two researchers involved in the interviews. The research proceeded in four steps. First, prior to the ISI interview, the first author provided a copy of the Australian edition of the SDS (Shears \& Harvey-Beavis, 2012) to the participant who completed this. Second, the first author conducted the reflective ISI interview with Nadya, the participant. The duration of the reflective ISI interview was 37 minutes. Third, an IPR interview was conducted with the participant and the fourth step involved an IPR interview with the interviewer. The fourth author acted as the inquirer for the IPR interviews with the participant and the interviewer.

The IPR interviews were conducted after a short break following the reflective ISI interview. At the beginning of each IPR interview, the inquirer explained the process and invited both the participant and the interviewer to listen to the recording, and to stop it at meaningful or significant points. The IPR interview enabled both the participant and the interviewer to review and recall the interview content, to reflect on it, and to provide further information or comment. The duration of the IPR interview with Nadya was 31 minutes, exclusive of the time taken to replay the reflective ISI interview. The participant was initially briefed by the inquirer that she had control of the audio-player and that she could pause the recording at any moment to add information, clarify, or reflect on the ISI interview. The inquirer asked minor questions at times when further clarification was needed. The same This is a pre-print version of:

McMahon, M., Bimrose, J., Watson, M., \& Abkhezr, P. (2019). Integrating storytelling and quantitative career assessment. International Journal for Educational and Vocational Guidance, 1-22. https://doi.org/10.1007/s10775-019-09415-1 
Integrating storytelling and assessment

procedure was repeated in the IPR interview between the inquirer and the interviewer. The duration of this inquiry with the interviewer was 46 minutes, exclusive of the time taken to replay the reflective ISI interview. Audio-recordings were transcribed, de-identified, and emailed to the participant for checking. The participant received de-identified transcripts of both interviews to read and comment further on them to improve confirmability of data. Nadya did not request any changes to her transcripts.

\section{Data analysis}

Qualitative content analysis was selected as a suitable approach for this single case study. It is defined as "a mixed methods approach (containing qualitative and quantitative steps of analysis)" (Mayring, 2014, p. 6) and comprises a holistic and subjective procedure that is used to interpret and categorise qualitative data. Its purpose is to condense extensive textual data (here, this was the transcript of the reflective interview) into a brief summary format. Qualitative content analysis is an analytical procedure for "the subjective interpretation of the content of text data through the systematic classification process of coding and identifying themes or patterns" (Hsieh \& Shannon, 2005, p. 1278) and has seen increasing usage and acceptance (Elo \& Kyngäs, 2008). It was chosen as the approach for analysis in this study since it is regarded as particularly suitable for case study research (Kohlbacher, 2006) and is consistent with the overall approach of combining the two dominant research traditions.

Qualitative content analysis has been described as essentially a coding process, with "coding being the process of transforming raw data into a standardized form" (Babbie, 2001, p. 309). Data were analysed both inductively and deductively by two researchers to ensure a rigorous and robust approach (Leech \& Onwuegbuzie, 2007). A transcript was produced from the recording of the interview with the research participant so that the textual data could be examined inductively. This involved open coding, creating categories and abstraction.

This is a pre-print version of:

McMahon, M., Bimrose, J., Watson, M., \& Abkhezr, P. (2019). Integrating storytelling and quantitative career assessment. International Journal for Educational and Vocational Guidance, 1-22. https://doi.org/10.1007/s10775-019-09415-1 
Initially, the second researcher who was not involved in the interviews independently read through the transcript, making brief notes and headings in the margin, to highlight major themes that were relevant or interesting to the research focus. After this open coding the notes and headings were organised into higher order subcategories according to the different types of information found. This reduced the number of categories by rationalising similar and dissimilar themes. Rationalising required comparison of the categories generated and identifying data not belonging to these categories so that the categories could be tightened and refined through a process of interpretation. Creating categories is the core feature of qualitative content analysis, with a number of subcategories at varying levels of abstraction (Graneheim \& Lundman, 2003). The emergent categories and subcategories were then reordered and linked through a process of abstraction to increase understanding and create knowledge (Elo \& Kyngäs, 2008).

The coding system was then scrutinized further by the first researcher against the transcript, with some revision and re-positioning of the codes. Several iterations of this process were undertaken before the first draft of the coding was produced. This was then sent to the second researcher who, again independently, examined the codes against the transcript. A number of queries and discrepancies were identified and discussed until resolved, resulting in minor revisions. All code categories were then reviewed once more to ascertain whether some could be merged or subcategorised. Finally, the second researcher, who developed the initial codes, returned to the original transcript to ensure that all the information that needed to be categorised could be included in the coding. As a result, two major codes, eight subcodes and three subcategories emerged from the data. The two major codes are: career sense-making and intra-individual insights.

This is a pre-print version of:

McMahon, M., Bimrose, J., Watson, M., \& Abkhezr, P. (2019). Integrating storytelling and quantitative career assessment. International Journal for Educational and Vocational Guidance, 1-22. https://doi.org/10.1007/s10775-019-09415-1 
Second, deductive content analysis was used to examine the reflective ISI interview and the IPR interview with the participant and the interviewer based on the five systemic process constructs of the story telling approach, specifically reflection, connectedness, meaning making, learning and agency (McMahon, 2005). The aim of deductive content analysis is to "give explicit definitions, examples and coding rules for each deductive category, determining exactly what circumstances a text passage can be coded with a category" (Mayring, 2000). Descriptors of the constructs (see McMahon, Watson, Chetty, \& Hoelson, 2012) were used to guide the data analysis. Specifically, the first author constructed a table of five rows according to the process constructs and their descriptors and examined the transcripts for excerpts of text that accorded with the construct which were then entered into the second column of the table. Because connectedness is a multileveled construct, the excerpts were further examined, and subcodes were identified including social, past experience, future role, past experience and SDS code letter, personal and work, and intrapersonal qualities and external events. This table was then sent to the second author who independently examined the constructs and subcodes against the excerpts. Queries and discrepancies were identified and discussed until resolved, resulting in minor revisions.

In addition, a second deductive analysis of the interviewer's contribution to the reflective interview was conducted using the story telling approach's three levels of story crafting questions proposed by McMahon and Watson (2012a). Level 1 story crafting questions seek informational stories of content and experience. Level 2 story crafting questions focus more on connectedness and recursiveness between stories and elements of stories and the client's subjective experience of the story. Level 3 story crafting questions invite reflection on "What does this say about you as a person?" and identifying themes and patterns that are present in all stories. The first author constructed a table of three rows This is a pre-print version of:

McMahon, M., Bimrose, J., Watson, M., \& Abkhezr, P. (2019). Integrating storytelling and quantitative career assessment. International Journal for Educational and Vocational Guidance, 1-22. https://doi.org/10.1007/s10775-019-09415-1 
according to the levels of story crafting questions and their descriptors and examined the transcripts for excerpts of text that accorded with the story crafting question level which were then entered into the second column of the table. This table was then sent to the second author who independently examined the levels against the excerpts. Queries and discrepancies were identified and discussed until resolved, resulting in minor revisions.

The trustworthiness of the research was ensured by application of Guba's (1981) four criteria of credibility, dependability, transferability and confirmability; these criteria are widely accepted in qualitative research (Shenton, 2004). In addition, strategies such as triangulation (Yin, 2015) and member checking (Merriam, 2002) were used. During the analysis the researchers extensively reviewed possible biases, reflected and discussed these with each other, and examined and revised their analysis until saturation was reached and credibility achieved (Baxter \& Jack, 2008). Dependability was accomplished by having the data analysed several times by conducting critical examinations of codes generated, and then reaching consensus on the emerging codes and categories to improve the consistency of the findings (Baxter \& Jack, 2008). Collecting thick descriptions of the participant's experiences that would allow readers to relate to her experiences contributed to transferability. The participant received de-identified transcripts of both interviews to read and comment on further to improve confirmability of data. Additionally, the iterative nature of the IPR interview assisted the researchers to become more reflexive about the process and so enhance issues related to confirmability (Elliott, 1986; Viney \& Nagy, 2012).

\section{Results}

Nadya's three-letter SDS code was ASE, i.e., a combination of artistic, social and business type interests. The reflective interview transcript contained 462 lines of text, of which 314 $(67.96 \%)$ were spoken by Nadya. The results related to the ISI will be presented first

This is a pre-print version of:

McMahon, M., Bimrose, J., Watson, M., \& Abkhezr, P. (2019). Integrating storytelling and quantitative career assessment. International Journal for Educational and Vocational Guidance, 1-22. https://doi.org/10.1007/s10775-019-09415-1 
beginning with the results from the inductive coding followed by the results of the deductive coding. Second, the results of the IPR interviews will be presented beginning with the participant followed by the interviewer.

\section{ISI Interview: Inductive Codes}

Results from the inductive coding of the transcript are presented according to the major codes, beginning with career sense-making and subsequently intra-individual insights.

Career sense-making. The first major content code that emerged was career sensemaking. Within this major content code, five subcodes were identified: career problem, career solution, career aspirations, career decision making style, and impact of the interview. Given the similarities between the subcodes and elements of the career counselling interviews, the major code was named career sense-making.

The first subcode, career problem, related to the employment market. The participant was undergoing a mid-career change. She had initiated a major set of transitions because her labour market situation had deteriorated: "I have been thinking about this for about a year and what my possible career could be". The occupational sector in which she had established her initial career pathway had become volatile. There was insufficient employment and a lack of stability. She had felt vulnerable and said that she had felt "a bit lost for a while".

The second subcode is career solution, which the participant regarded as working towards an improvement in her socioeconomic status. She expressed her wish for "a better income and some stability". These, she hoped, would result from the career transition in which she was engaged. In fact, she reported that she had already achieved a measure of success in this regard, since someone she had connected with, as a result of studying on her course, had offered her part-time work: "Well, the most tangible thing is that it's kind of someone I met got me the job, in a way, through the course". Consequently, she was able to This is a pre-print version of:

McMahon, M., Bimrose, J., Watson, M., \& Abkhezr, P. (2019). Integrating storytelling and quantitative career assessment. International Journal for Educational and Vocational Guidance, 1-22. https://doi.org/10.1007/s10775-019-09415-1 
envision a different future for herself, which would involve maintaining her interests and skills in aspects of her previous occupational role, combining these with the part-time employment that she had secured.

The third subcode that emerged was career aspirations. Having worked towards transition in the occupational sector by undertaking an additional educational qualification that would qualify her for a particular role, she was already orienting towards another transition within the same broad sector, but at a different level: "But if the [job] one day leads somewhere else ... I actually wouldn't mind doing a Master's degree in the future. I don't know where that could end up". She was open to possibilities and willing to commit to further training if need be.

Career decision making style emerged as the fourth subcode. Four different approaches to career decision making by adults were identified from qualitative research conducted for a five-year longitudinal study into the effectiveness of career counselling in England (Bimrose, Barnes, \& Hughes, 2008). The participant described her propensity to be opportunistic in her approach, reflecting one of these four approaches: "I suppose opportunities as they come up will take my interest". This tendency had been rewarded, as events had unfolded while she had been studying on her course: "Around the time I started looking for jobs and applying for other jobs, I got an email from him saying would I be interested?" Valuing the potential to learn and earn at the same time, she had not underestimated the value of developing new skills sets, alongside the opportunity to develop new networks.

The fifth and final subcode within the major code of career sense-making relates to the impact of the interview. The participant was positive about her experience of the

This is a pre-print version of:

McMahon, M., Bimrose, J., Watson, M., \& Abkhezr, P. (2019). Integrating storytelling and quantitative career assessment. International Journal for Educational and Vocational Guidance, 1-22. https://doi.org/10.1007/s10775-019-09415-1 
interview. She felt that it had been beneficial because it had been confirmatory: "Yeah, there wasn't a lot of new things that I saw in this booklet that was revelatory to me".

\section{Intra-individual Insights}

This major content code was derived from three subcodes, self-awareness, values, and world of work knowledge, all of which were specific to Nadya. Hence, the major content code was termed Intra-individual Insights.

Self-awareness is one of the three subcodes that emerged within this second major content code. It relates to the clarity with which the interview participant sees herself in relation to her world. Three further subcategories emerged within the subcode of selfawareness: motivation, circumstances and self-concept. First, the participant was aware of the motivation that brought her to this transitionary stage in her mid-career, reflecting that, even though she has made a major commitment to a different (vocational) training pathway that will equip her for entry to a profession, this change had not been driven by strong feelings. Rather the participant felt that: "It's not been really a great passion of mine to [work in new occupation], it just is, kind of, the logical thing". Second, she was aware of her relatively favourable circumstances. She reflected on how she was able to make this significant lifestyle change because of her lack of care responsibilities and her financial situation:

I was lucky that I had a bit of savings and I could just spend a year on that and not have to do anything else very much. I don't think I could have coped with a family or a baby.

Third, the participant had a clear self-concept regarding both how she operates and the greatest influences on this work style:

This is a pre-print version of:

McMahon, M., Bimrose, J., Watson, M., \& Abkhezr, P. (2019). Integrating storytelling and quantitative career assessment. International Journal for Educational and Vocational Guidance, 1-22. https://doi.org/10.1007/s10775-019-09415-1 
But maybe from schooling and the discipline that came from practice, and also seeing how my dad works very hard and stuff, maybe it's just a habit, in a way, of just being - I'm not very organised, really, but I work solidly and consistently.

The second subcode within the major code of intra-individual insights is values. The participant reflected on the ways in which her personal values frame her behaviours: "I don't, you know, break trust or anything. I'm honest and I won't recommend a product if I don't think it's good or right for them". She was also aware about her need to establish balance in her working life: “But I don't want to be exhausting myself. I want to put good energy into the [new job role]". In addition, she was aware of how she derives job satisfaction: "I did tutor some students...they both did really well...so that was a proud moment, that was pretty inspiring...just little landmarks along the way, of progress, I guess would be satisfying”.

The third subcode is world of work knowledge. The participant showed an accurate understanding of labour market requirements in relation to the skills and qualities that would be required:

You have to organise your invoices and all that, do that kind of stuff...plus you have to promote yourself a little bit ... things like reliability are very important for an employer or colleagues. Yeah, if you're dependable and you'll be on time and honest. Logical things, I guess.

Nadya recognised her accumulated work experience as an asset: "I've worked in a lot of workplaces before and so it's not going to be [a] huge shock to me like it would be to someone who's come straight through school-uni-job". She was also clear about the labour market value of her educational qualifications: "I've got that piece of paper.... And actually have now got a job" and the way this gave her options:

This is a pre-print version of:

McMahon, M., Bimrose, J., Watson, M., \& Abkhezr, P. (2019). Integrating storytelling and quantitative career assessment. International Journal for Educational and Vocational Guidance, 1-22. https://doi.org/10.1007/s10775-019-09415-1 
I wasn't sure at the start of the year whether I would actually even want to do that, but at least having this would give me the options... I've spent this time so I might as well try and give it my best shot.

\section{ISI Interview: Deductive Codes}

The process constructs of the story telling approach, specifically reflection, connectedness, meaning making, learning and agency were used to code the participant's responses in the interview. Data analysis revealed discrete examples of each construct as well as examples of recursiveness between the constructs. For example, reflection was evident as a discrete construct in the subjectivity and thoughtfulness expressed when Nadya considered beginning her new job:

I'm a bit nervous. I am a bit nervous, because it's come around quickly. It's just the unknown. I think the thing that's concerning me most is just getting through the first few weeks, because I really don't know how it works ... it's the stuff I don't know about yet. But I think there'll be people to help with that and tell me where I should be when and all that.

Connectedness was evident as a multi-levelled systemic construct that illustrated relationships between elements of Nadya's stories. For example, social connectedness was evident in Nadya's comment about how she found a job after completing her course of study: "It's kind of someone I met got me the job, in a way, through the course". Connectedness between past, present and future experiences was evident in Nadya's belief that her previous work transitions had to some extent prepared her for her next transition into her new job: "I've worked in a lot of workplaces before and so it's not going to be a huge shock to me like it would be to someone who's come straight through school-uni-job". A further example of

This is a pre-print version of:

McMahon, M., Bimrose, J., Watson, M., \& Abkhezr, P. (2019). Integrating storytelling and quantitative career assessment. International Journal for Educational and Vocational Guidance, 1-22. https://doi.org/10.1007/s10775-019-09415-1 
connectedness was evident between Nadya's personal qualities and her previous and future employment when she reflected:

A good work ethic. I think a good manner with people, where you can just chat and they're comfortable talking, especially in sales. I think I have a bit of a knack for that, because people generally feel comfortable and chat and trust me.

Meaning making was evident as Nadya considered the A and S in her three-letter code and explained them in her own way:

I guess its self-expression, really, and an outlet for energy and creativity. Because if you're in ... groups, you're all working together to create something, hopefully. It's also sort of networking and going to see other people ... and chatting and doing that stuff. So it does tie in ... Then, I do like people, so I like to talk and get to know people and travel and see different cultures... maybe $S$ has to go a bit higher on the scale.

Learning was apparent in the new realisation Nadya came to in her statement related to her S code and her future occupation: "I guess ... comes under S for social occupation, so that's interesting. So that fits in with my new ... career and interest in helping young people, I suppose". Agency was evident in Nadya's taking responsibility for her decision making which signalled her intent and also in her subsequent actions. For example, she commented that: "I decided probably to get something more stable", which resulted in action: "I took a year out where I was doing bits and pieces of other work and thought over what my options were, really". Agency was also evident in her comment that: "I started looking at jobs in December, I think, or November - November, actually. I had this one lined up within a couple of weeks of that".

This is a pre-print version of:

McMahon, M., Bimrose, J., Watson, M., \& Abkhezr, P. (2019). Integrating storytelling and quantitative career assessment. International Journal for Educational and Vocational Guidance, 1-22. https://doi.org/10.1007/s10775-019-09415-1 
In addition to examples of the process constructs that were discrete, examples of recursiveness between constructs were found. Of the nine recursive examples coded, reflection was apparent in eight. For example, recursiveness between reflection and learning was apparent in Nadya's comment that:

I guess it comes down to earning a decent amount of money. Because I'm getting older and I think I'm less idealistic now about needing money or not needing money and following the dream or whatever. Yeah, I think I'm just tired of not having enough money, so I think ... is a good option.

Recursiveness between reflection, meaning making and connectedness was evident as Nadya tried to understand her E code:

Enterprising, I can kind of see from my retail sales and my little business. Plus, being a ..., you have your ABN [Australian Business Number] and you have to organise your invoices and all that, do that kind of stuff. I guess it fits there. Plus, you have to promote yourself a little bit, so they seem to tie in with what I do.

The interviewer contribution to the reflective ISI interview was coded according to the three levels of story crafting questions (McMahon \& Watson, 2012a). Level 1 story crafting questions were coded 14 times with over half of these being contained in the first third of the interview. Examples of Level 1 story crafting questions include: "I'd be really keen to know what employment you had prior to coming to university" and "How do you know when an opportunity sort of speaks to you?" Level 2 story crafting questions were coded 17 times and were evident throughout the interview. Examples of Level 2 story crafting questions include: "I'm just curious to know ... what was the impact of coming back to university on your lifestyle?" and "So what have you learnt that will actually prepare you to move from university to this job?". Level 3 story crafting questions were coded 10 times, This is a pre-print version of:

McMahon, M., Bimrose, J., Watson, M., \& Abkhezr, P. (2019). Integrating storytelling and quantitative career assessment. International Journal for Educational and Vocational Guidance, 1-22. https://doi.org/10.1007/s10775-019-09415-1 
with the first example being coded over one third of the way into the interview at line 192 of the transcript. Examples of Level 3 story crafting questions include: "So how would you explain those letters, like the A, in terms of what you've done and what you hope to do ..." and "How would you explain those experiences in relation to your code?"

\section{IPR: Participant}

The five process constructs of the story telling approach, specifically reflection, connectedness, meaning making, learning and agency were used to code the participant's stories in the IPR interview. As with the ISI interview, the data analysis revealed discrete examples of each construct as well as examples of recursiveness between the constructs. An example of the process construct reflection was Nadya's comment: "Yeah, the more you think about these things, the more you remember or realise, oh yeah, that's right, they did help me". She also reflected that: "It's good, actually, because it makes you really think through in great detail and break it down into those categories". Connectedness was evident in Nadya's comments on the participant-interviewer relationship: "I mean, it just felt like I was just chatting about a lot of things that I've done" and in her comment on the interview content: "So I was thinking back to the past a bit, but also thinking forward". Nadya commented about the E from her three-letter code in a statement that reflected meaning making: "I think that also coincides with E, enterprising. Because for the networking and chasing up more work for yourself and promoting yourself, that comes into it. I think I could actually be a lot better at promotion, but I don't like self-promotion”. As Nadya considered her future salary, a learning that she became aware of was:

I was just thinking, having that regular money every fortnight will allow me to be more choosy about what other things I take on ... I won't have to do some horrible [job] for $\$ 100$, I can wait and just do one that I want to do.

This is a pre-print version of:

McMahon, M., Bimrose, J., Watson, M., \& Abkhezr, P. (2019). Integrating storytelling and quantitative career assessment. International Journal for Educational and Vocational Guidance, 1-22. https://doi.org/10.1007/s10775-019-09415-1 
Agency was apparent in Nadya's realisation that:

With the shop I work for ... they don't want me to leave. So, I've basically got options, which is great ... if I really don't want to [practice] ... which I don't think is going to happen ... I've got that option to come back to.

As with the ISI interview, the process constructs were also coded in combination which indicated a recursive relationship between them. The following illustrative example demonstrates recursiveness between reflection, meaning making, learning, and connectedness:

That booklet [the SDS] probably would have helped me a year ago ... before I decided to [study] ... I was a bit, like I said, lost, just in terms of what do I do now to transition from this ... lifestyle to a more settled one ... I think that booklet would have probably been good then. But anyway ... it seems like I'm on the path that it would recommend.

At the beginning of the ISI interview, Nadya explained that her reason for participating in the research was to "get some clarity on ... if I have made the right choice" with her recent decision to study and transition to a new occupation. In the IPR interview, Nadya revealed that the interview "was pretty comprehensive" and that "It's good, actually, because it makes you really think through in great detail and break it down into those categories". Thus, it seems that through a combination of the SDS and the ISI interview, Nadya achieved the "clarity" that she wanted.

\section{IPR: Interviewer}

The IPR interview provided the interviewer with an opportunity to reflect on the decisions she made during the interview, her feelings towards the participant, her reactions to the participant's stories and her interview decisions. Data analysis revealed that conducting the This is a pre-print version of:

McMahon, M., Bimrose, J., Watson, M., \& Abkhezr, P. (2019). Integrating storytelling and quantitative career assessment. International Journal for Educational and Vocational Guidance, 1-22. https://doi.org/10.1007/s10775-019-09415-1 
interview was both an objective and subjective process for the interviewer. The process constructs of the story telling approach, specifically reflection, connectedness, meaning making, learning and agency were used to code the interviewer's responses in the IPR interview. Two examples that are illustrative of reflection demonstrate the interviewer's subjective experience of the interview, specifically: "I was actually really excited that there were some really genuine reasons about this participant coming into the study" and "I was really surprised by this, that again she shared ... her anxiety ... and her vulnerability and talking about sleepless nights". Connectedness was evident in the interviewer's comments about the participant-interviewer relationship: "as our relationship developed in the interview... I was aware of her exposing some vulnerability and I was very appreciative of her honesty in doing that". The subjective nature of the interview is also reflected in this example. Meaning making concerned how the interviewer began to make sense of the participant's progress in understanding her code as reflected in the following statement: I could really see her coming to understand S more in the context of her life ... she was making sense of her three-letter code much, much more ... she identified a number of different facets of her life ... I had a sense she was beginning to see the $\mathrm{S}$ as a bit of a theme that went through her life, where I didn't think she had that at the beginning of the interview.

Learning was evident in an experience described by the interviewer: "I really found myself very interested in what she was saying and learning from her about a career that I know virtually nothing about. So yeah, I felt like I was the learner in this little interaction". Examples of agency related to the nature of the objective decisions made by the interviewer during the reflective interview as illustrated by the comment: "I felt I couldn't continue on without clarifying something about her occupation ... That would have been one of the This is a pre-print version of:

McMahon, M., Bimrose, J., Watson, M., \& Abkhezr, P. (2019). Integrating storytelling and quantitative career assessment. International Journal for Educational and Vocational Guidance, 1-22. https://doi.org/10.1007/s10775-019-09415-1 
questions that I could have asked earlier". A further example illustrated the objective nature of a decision made by the interviewer: "I had wanted to ask a question about what her thoughts were about ... I let that one pass because, by the time she had spoken a little bit more ... I would have been backtracking to go there".

\section{Discussion}

As reflected in the results, qualitative description provides a detailed and nuanced understanding (Sandelowski, 2000) of the ISI (McMahon \& Watson, 2012b) for Holland's (1985) SDS. The encouraging results that have emerged from qualitative content analysis should be considered, however, in the context of the limitations of the research, specifically that the article reports on one interview with one female participant in one national context, Australia. Moreover, the content analysis did not seek a deep level of interpretation because it focused on facilitating a rich understanding of the data by staying close to emergent categorisations (Mayring, 2014).

During the ISI interview, the participant spoke for more than two-thirds of the interview time which suggests that she felt safe to reflect, answer questions and elaborate her responses to the ISI questions. Qualitative research such as this is founded on a relationship and interaction between the interviewer and the participant and so rapport building is important for the participant to feel safe enough to respond to the interviewer's questions (Dickson-Swift, James, Kippen, \& Liamputtong, 2006; Richardson, 2005). Similarly, much is made in narrative career counselling of the need to provide a safe reflective space for clients (McMahon, 2005; McMahon et al., 2012; Patton \& McMahon, 2014; Reid \& Bassot, 2011; Watson \& McMahon, 2014). Authors such as Dickson-Swift et al. and Richardson have discussed the boundary issues that can sometimes emerge in qualitative research between research and counselling. Similarly in qualitative career research, boundary issues have been This is a pre-print version of:

McMahon, M., Bimrose, J., Watson, M., \& Abkhezr, P. (2019). Integrating storytelling and quantitative career assessment. International Journal for Educational and Vocational Guidance, 1-22. https://doi.org/10.1007/s10775-019-09415-1 
considered (Abkhezr, McMahon, Campbell, \& Glasheen, in press). The researcher monitored this boundary by being guided by the interview questions and using probes where necessary. This research suggests that the ISI interviewer role should be that of a facilitator or inquirer. Moreover, the interview demonstrates how integrative narrative processes can be used to qualitatively reflect on quantitative scores.

The major codes, subcodes and subcategories generated through the qualitative inductive content coding are reflective of the themes recurring across Nadya's stories. Of interest, is the major code titled Career Sense-making. While the research was not based on an intervention, Nadya experienced some reassurance from her participation. This is consistent with the relational nature of qualitative research where it is not uncommon for participants to experience benefits and change to occur (Dickson-Smith et al., 2006; Richardson, 2005).

During the course of the interview, change was evident in several ways. First, the participant moved from a position of wanting clarity about her recent career decision and transition to feeling that she was following the right path. Across the interview, she began to make more sense of her three-letter code in the context of her past, present and future experiences in a range of life contexts as the interview progressed. Second, the relationship between the interviewer and participant deepened and strengthened across the interview as reflected by the participant's willingness to express her vulnerability. Third, the nature of the story crafting questions asked by the interviewer varied across the interview. In the first half of the interview, Level 1 and Level 2 questions were more evident, whereas Level 3 questions that concern themes and patterns were more evident in the latter part of the interview.

This is a pre-print version of:

McMahon, M., Bimrose, J., Watson, M., \& Abkhezr, P. (2019). Integrating storytelling and quantitative career assessment. International Journal for Educational and Vocational Guidance, 1-22. https://doi.org/10.1007/s10775-019-09415-1 
This suggests that the information gathering facilitated by Level 1 questions provides a foundation for subsequent Level 3 questions that then provide a synthesising function through the identification of themes and patterns. It also suggests that Level 2 questions which were evident across the interview provide a bridging function that connects stories and taps participants' subjective experience of the stories, both of which contribute to the generation of unifying themes and patterns. Further research is needed to establish the utility of the levels of the story crafting questions and their role in narrative career counselling interviews.

Contributing to the changes outlined was the nature of the interview and the role of the interviewer in building a respectful, safe environment. Specifically, the interviewer was a facilitator of a research process that gave space for the participant to reflect on her three-letter code and her past, present and future experiences in a range of life contexts. Indeed, the interviewer spoke for less than one-third of the interview time. The participant actively participated in the research by providing rich and detailed answers to questions which stimulated the curiosity of the interviewer who further probed the participant's responses, thus demonstrating interest in her story and that she mattered. The interviewer also invited the participant to reflect more deeply and make connections that were not previously possible for her. As the interview progressed, the nature of the story crafting questions asked by the interviewer changed to include more Level 3 questions that focused on themes and patterns across stories and personal meaning. Throughout the interview, the participant actively participated and willingly told her stories and at times expressed her vulnerability.

Reflexivity was fostered throughout the interview by the nature of the ISI questions and the subsequent probes asked by the interviewer, and also by the nature of the safe reflective space provided to the participant who spoke for over two thirds of the interview This is a pre-print version of:

McMahon, M., Bimrose, J., Watson, M., \& Abkhezr, P. (2019). Integrating storytelling and quantitative career assessment. International Journal for Educational and Vocational Guidance, 1-22. https://doi.org/10.1007/s10775-019-09415-1 
time. This process was illustrative of Reid and Bassot's (2011) claim that "reflexivity can enable the career counsellor to work alongside the client as a useful partner in the construction of career goals" (p. 113). Despite being guided by an interview structure, the ISI process encourages interviewers to probe participant responses to assist with further reflection and clarification which in turn stimulates meaning making and learning.

Deductive content analysis using the five process constructs of reflection, connectedness, meaning making, learning and agency as described by McMahon et al. (2012) proved useful in better understanding the process of the ISI interview. Given that the ISI has its theoretical foundation in the STF, the example of how the process constructs manifested in the interview provided examples of the theory-practice relationship. The deductive content analysis also proved powerful in analysing the IPR interview. While discrete examples of each construct could be identified in each interview, many examples were evident of a recursive relationship that exists between the constructs. Moreover, a recursive relationship seemed more evident between reflection and other constructs than between other constructs, possibly suggesting that reflection assumes a more overarching function. Further research is needed, however, to establish the efficacy of this approach given the preliminary nature of this form of data analysis. Given that the research is based on a single case study, future research could examine the use of the ISI in career counselling a range of client groups.

\section{Conclusion}

An emergent need has been to find ways to integrate quantitative career assessment with career counselling approaches that place greater emphasis on stories than on scores, for the greater benefit of clients. The Integrative Structured Interview for the Self-Directed Search which guided the interview reported in this article clearly demonstrates how, through a combination of storytelling and quantitative career assessment, a rich integrative process can This is a pre-print version of:

McMahon, M., Bimrose, J., Watson, M., \& Abkhezr, P. (2019). Integrating storytelling and quantitative career assessment. International Journal for Educational and Vocational Guidance, 1-22. https://doi.org/10.1007/s10775-019-09415-1 
be facilitated that enabled the participant to contextualise, make sense of, and learn from her scores, career decisions and transitions. The use of qualitative content analysis made the richness of the ISI transparent as revealed by the major codes, subcodes and subcategories. That the participant's goal for participating in the research was achieved lends support to the use of the ISI and suggests that it could be a useful approach in career counselling.

This is a pre-print version of:

McMahon, M., Bimrose, J., Watson, M., \& Abkhezr, P. (2019). Integrating storytelling and quantitative career assessment. International Journal for Educational and Vocational Guidance, 1-22. https://doi.org/10.1007/s10775-019-09415-1 


\section{References}

Abkhezr, P. McMahon, M., Campbell, M., \& Glasheen, K. (In press). Exploring the boundary between narrative research and narrative intervention: Implications of participating in narrative inquiry for young people with refugee backgrounds. Narrative Inquiry.

Babbie, E. (2001). The practice of social research $\left(9^{\text {th }}\right.$ ed.) Belmont, CA: Wadsworth.

Baxter, P., \& Jack, S. (2008). Qualitative case study methodology: Study design and implementation for novice researchers. The Qualitative Report, 13, 544-559.

Bimrose, J., Barnes, S -A., \& Hughes, D. (2008). Adult career progression and advancement: A five year study of the effectiveness of guidance. Report to Government. London: Warwick Institute for Employment Research, Department for Education \& Skills. Retrieved from: http://www2.warwick.ac.uk/fac/soc/ier/publications/2008/eg_report_4_years_on_final .$p d f$

Cardoso, P., Goncalves, M. M., Duarte, M. E., Silva, J. R., \& Alves, D. (2016). Life Design Counseling outcome and process: A case study with an adolescent. Journal of Vocational Behavior, 93, 58-66. doi: 10.1016/j.jvb.2016.01.002

Dickson-Swift, V., James, E. L., Kippen, S., \& Liamputtong, P. (2006). Qualitative Health Research, 16, 853-871. doi: 10.1177/1049732306287526

Elliott, R. (1986). Interpersonal process recall (IPR) as a psychotherapy process research method. In W. M. Pinsof \& L. S. Greenberg (Eds.), The psychotherapeutic process: A research handbook (pp. 503-528). New York: Guilford Press.

Elo, S., \& Kyngäs, H. (2008). The qualitative content analysis process. Journal of Advanced Nursing, 62, 107 - 115. doi:10.1111/j.1365-2648.2007.04569.x

This is a pre-print version of:

McMahon, M., Bimrose, J., Watson, M., \& Abkhezr, P. (2019). Integrating storytelling and quantitative career assessment. International Journal for Educational and Vocational Guidance, 1-22. https://doi.org/10.1007/s10775-019-09415-1 
Graneheim, U.H., \& Lundman, B. (2003). Qualitative content analysis in nursing research: Concepts, procedures and measures to achieve trustworthiness. Nurse Education Today, 24, 105-112. doi:10.1016/j.nedt.2003.10.001

Guba, E. G. (1981). Criteria for assessing the trustworthiness of naturalistic inquiries. Educational Communication and Technology Journal, 29, 75-91. doi:10.1007/BF02766777

Hartung, P. J., \& Vess, L. (2016). Critical moments in career construction counseling. Journal of Vocational Behavior, 97, 31-39. doi: 10.1016/j.jvb.2016.07.014

Heppner, M. J., \& Heppner, P. P. (2003). Identifying process variables in career counseling: A research agenda. Journal of Vocational Behavior, 62(3), 429-452. doi: $10.1016 / \mathrm{S} 0001-8791(02) 00053-2$

Holland, J. L. (1985). The Self-Directed Search: A guide to educational and vocational planning. Odessa, FL: Psychological Assessment Resources.

Holland, J. L. (1997). Making vocational choices: A theory of vocational personalities and work environments ( $3^{\text {rd }}$ ed.) Odessa, FL: Psychological Assessment Resources.

Hsieh, H-F., \& Shannon, S.E. (2005). Three approaches to qualitative content analysis. Qualitative Health Research, 15, 1277-1288. doi: 10.1177/1049732305276687 Kagan, N. (1980). Influencing human interaction: Eighteen years with IPR. In A. K. Hess (Ed.), Psychotherapy supervision: Theory, research, and practice (pp. 262-283). Toronto, ON: John Wiley.

Kagan, N. (1984). Interpersonal process recall: Basic methods and recent research. In D. Larson (Ed.), Teaching psychological skills: Models for giving psychology away (pp. 229-244). Monterey, CA: Brooks/Cole.

This is a pre-print version of:

McMahon, M., Bimrose, J., Watson, M., \& Abkhezr, P. (2019). Integrating storytelling and quantitative career assessment. International Journal for Educational and Vocational Guidance, 1-22. https://doi.org/10.1007/s10775-019-09415-1 
Kohlbacher, F. (2006). The use of qualitative content analysis in case study research. Qualitative Social Research, 7, 1-30. doi: 10.17169/fqs-7.1.75

Larsen, D., Flesaker, K., \& Stege, R. (2008). Qualitative interviewing using interpersonal process recall: Investigating internal experiences during professional-client conversations. The International Journal of Qualitative Methods, 7(1), 18-37. doi: $10.1177 / 160940690800700102$

Leech, N. A., \& Onwuegbuzie, A. J. (2007). An array of qualitative data analysis tools: A call for data analysis triangulation. School Psychology Quarterly, 22, 557-584. doi: $10.1037 / 1045-3830.22 .4 .557$

Mayring, P. (2000). Qualitative content analysis. Qualitative Social Research, 1, 1-7. doi: 10.17169/fqs-1.2.1089

Mayring, P. (2014). Qualitative content analysis: Theoretical foundation, basic procedures and software solution. Available from: https://nbn-resolving.org/urn:nbn:de:0168ssoar-395173

McMahon, M. (2005). Career counseling: Applying the Systems Theory Framework of career development. Journal of Employment Counseling, 42 (1), 29-38. doi: 10.1002/j.21611920.2005.tb00896.x

McMahon, M., \& Watson, M. (2010). Storytelling: Moving from thin stories to thick and rich stories. In K. Maree (Ed.), Career counselling: Methods that work (pp. 53-63). Cape Town, South Africa: Juta.

McMahon, M., \& Watson, M. (2012a). Story crafting: Strategies for facilitating narrative career counselling. International Journal for Educational and Vocational Guidance, 12(3), 211-224. doi: 10.1007/s10775-012-9228-5

This is a pre-print version of:

McMahon, M., Bimrose, J., Watson, M., \& Abkhezr, P. (2019). Integrating storytelling and quantitative career assessment. International Journal for Educational and Vocational Guidance, 1-22. https://doi.org/10.1007/s10775-019-09415-1 
McMahon, M., \& Watson, M. (2012b). Telling stories of career assessment. Journal of Career Assessment, 20(40), 440-451. doi: 10.1177/1069072712448999

McMahon, M., \& Watson, M. (2015). Career assessment: Qualitative approaches. Rotterdam, The Netherlands: Sense.

McMahon, M., Watson, M., Chetty, C., \& Hoelson, C. N. (2012). Examining process constructs of narrative career counselling: An exploratory case study. British Journal of Guidance \& Counselling, 40(2), 127-141. doi:10.1080/03069885.2011.646949

McMahon, M., Watson, M., \& Lee, M. C. Y. (2018). Qualitative career assessment: A review and reconsideration. Journal of Vocational Behavior. 110 Part B, 420-432. doi: 10.1016/j.jvb.2018.03.009

McMahon, M., Watson, M., \& Zietsman, L. (2018). Adults changing careers through university education: Making meaning of quantitative career assessment scores through an integrative structured interview. South African Journal of Industrial Psychology, 44, 1-10. doi: 10.4102/sajip.v44i0.1487

Merriam, S. B. (2002). Qualitative research in practice: Examples for discussion and analysis. San Francisco, CA: Jossey-Bass.

Patton, W., \& McMahon, M. (2014). Career development and systems theory: Connecting theory and practice ( $3^{\text {rd }}$ ed.). Rotterdam, The Netherlands: Sense.

Reid, H., \& Bassot, B. (2011). Reflection: A constructive space for career development. In M. McMahon \& M. Watson (Eds.), Career counselling and constructivism: Elaboration of constructs (pp. 101-115). New York: Nova Science.

Richardson, M. S. (2005). Implications of the paradigms of constructivism and social constructionism: A challenge to traditional boundaries between research and intervention. Paper presented at a symposium on Constructivism and Vocational

This is a pre-print version of:

McMahon, M., Bimrose, J., Watson, M., \& Abkhezr, P. (2019). Integrating storytelling and quantitative career assessment. International Journal for Educational and Vocational Guidance, 1-22. https://doi.org/10.1007/s10775-019-09415-1 
Psychology at the Society for Vocational Psychology's $7^{\text {th }}$ Biennial Conference, Vancouver, British Columbia, June 2.

Ritchie, J., Lewis, J., McNaughton Nicholls, C., \& Ormston, R. (Eds.). (2013). Qualitative research practice: A guide for social science students and researchers. London, UK: Sage.

Sampson, J. P., Jr. (2009). Modern and postmodern career theories: The unnecessary divorce. The Career Development Quarterly, 58, 91-96. doi: 10.1002/j.21610045.2009.tb00178.x

Sampson, J. P., Jr., Peterson, G. W., Osborn, D. S., \& Hayden, S. C. (2015). Using career theory to integrate qualitative and quantitative career assessment. In M. McMahon \& M. Watson (Eds.), Career assessment: Qualitative approaches (pp. 181-190). Rotterdam, The Netherlands: Sense.

Sandelowski, M. (2000). Whatever happened to qualitative description? Research in Nursing and Health, 23, 334-340. doi: 10.1002/1098-240X(200008)23:4<334::AIDNUR9>3.0.CO;2-G

Schultheiss, D. E. (2017). Integrating theory, research, and practice in vocational psychology: Perspectives of a Journal of Vocational Behavior editorial board member. In J. P. Sampson, E. Bullock-Yowell, V. C. Dozier, D. S. Osborn, \& J. G. Lenz (Eds.), Integrating theory, research, and practice in vocational psychology: Current status and future directions (p. 166-174). Tallahassee, FL: Florida State University. doi: 10.17125/svp2016.ch17

Shears, M., \& Harvey-Beavis, A. (2012). The Self-Directed Search: A guide to educational and vocational planning (Australian Edition). Melbourne, Australia: ACER Press.

This is a pre-print version of:

McMahon, M., Bimrose, J., Watson, M., \& Abkhezr, P. (2019). Integrating storytelling and quantitative career assessment. International Journal for Educational and Vocational Guidance, 1-22. https://doi.org/10.1007/s10775-019-09415-1 
Shenton, A. K. (2004). Strategies for ensuring trustworthiness in qualitative research projects. Education for Information, 22, 63-75. doi: 10.3233/EFI-2004-22201

Super, D. E. (1957). The psychology of careers. New York: Harper and Row.

Viney, L. L., \& Nagy, S. (2012). Qualitative methods in personal construct research: A set of possible criteria. In P. Caputi, L. L. Viney, B. M. Walker, \& N. Crittenden (Eds.), Personal construct methodology (pp. 53-68). Chichester, UK: John Wiley.

Watson, M. (2016). Career development in changing world contexts: Reconstructing the wheels of theory and practice. CEAV (Career Education Association of Victoria) $e$ Journal, 43, 13-18.

Watson, M. (2017). Bridging quantitative and qualitative career assessment: The Integrative Structured Interview process. In M. McMahon (Ed.), Career counselling: Constructivist approaches ( $2^{\text {nd }}$ ed., pp. 260-269). London, UK: Routledge.

Watson, M., \& McMahon, M. (2014). Making meaning of quantitative assessment in career counseling through a storytelling approach. In G. Arulmani, A. J. Bakshi, F. T. L. Leong, \& A. G. Watts (Eds.), Handbook of career development: International perspectives (pp. 631-644). Heidelberg, Germany: Springer.

Watson, M., \& McMahon, M. (2015a). An introduction to career assessment. In M. McMahon \& M. Watson (Eds.), Career assessment: Qualitative approaches (pp. 311). Rotterdam, The Netherlands: Sense.

Watson, M., \& McMahon, M. (2015b). Integrative Structured Interview Process. In M. McMahon \& M. Watson (Eds.), Career assessment: Qualitative approaches (pp.199205). Rotterdam, The Netherlands: Sense.

This is a pre-print version of:

McMahon, M., Bimrose, J., Watson, M., \& Abkhezr, P. (2019). Integrating storytelling and quantitative career assessment. International Journal for Educational and Vocational Guidance, 1-22. https://doi.org/10.1007/s10775-019-09415-1 
Integrating storytelling and assessment

Watson, M., \& McMahon, M. (2018). Career assessment and creativity: Potential complementarity or a contradiction in terms? British Journal of Guidance and Counselling. doi: 10.1080/03069885.2018.1476835

Yin, R. K. (2015). Qualitative research from start to finish ( $2^{\text {nd }}$ ed.) New York: Guilford Press.

Zytowski, D. G. (2006). Super's work value inventory revised. Technical manual. Adel, IA: Kuder.

This is a pre-print version of:

McMahon, M., Bimrose, J., Watson, M., \& Abkhezr, P. (2019). Integrating storytelling and quantitative career assessment. International Journal for Educational and Vocational Guidance, 1-22. https://doi.org/10.1007/s10775-019-09415-1 